\title{
Análisis del lenguaje educomunicativo de los museos arqueológicos españoles durante el confinamiento de 2020
}

Analysis of the educational-communicative language of Spanish archaeological museums during the 2020 confinement

Iñaki Navarro-Neri, Borja Aso, Ana Mendioroz-Lacambra $\left({ }^{*}\right)$

\section{Resumen}

El cierre físico forzoso de los museos y yacimientos arqueológicos españoles vivido durante los primeros compases de la crisis sanitaria entre marzo y junio de 2020, obligó a las instituciones a volcar su actividad divulgativa y educativa en redes sociales tales como Facebook, Twitter o Instagram. E sta i nvestigación t iene c omo obj etivo analizar s i es tos es pacios arqueológicos utilizan un lenguaje educomunicativo acorde con la plataforma social en la que se encuentran, a partir del análisis de su producción comunicativa online en Twitter durante los primeros cien días de la c risis oc asionada por la c ovid-19 (de m arzo a j unio de 2020). Los r esultados muestran cómo las instituciones museísticas españolas pertenecientes al ámbito arqueológico más activas en Twitter -ya antes de la pandemia-, no solo han demostrado tener perfectamente interiorizado el lenguaje educomunicativo, sino que, a demás, con la situación sobrevenida de crisis s anitaria y c ierre forzoso de la actividad física, o ptaron $\mathrm{p}$ or am pliar y diversificar s u contenido. $\mathrm{De}$ i gual $\mathrm{m}$ anera, instituciones has ta ent onces menos ac tivas e $\mathrm{n}$ es ta plataforma, desarrollaron una actividad educomunicativa planificada y atractiva para todos los públicos.

Palabras Clave: educomunicación digital; museos ar queológicos y de sitio; medios sociales; Twitter; covid-19.

\begin{abstract}
The forced ph ysical c losure of $S$ panish $m$ useums a nd ar chaeological $s$ ites du ring the ear ly stages of the health crisis between March and June 2020 obliged the institutions to focus their informative and e ducational ac tivity o $\mathrm{n} s$ ocial networks $s$ uch as $\mathrm{F}$ acebook, Twitter an $\mathrm{d}$ Instagram. This $r$ esearch ai $m s t o$ anal yse whether $t$ hese ar chaeological $s$ ites us $e$ an educational-communicative language in accordance with the social platform they are on, based on the analysis of their online communicative production on Twitter during the first hundred days of the crisis caused by covid-19 (from March to June 2020).

The results s how how the S panish m useum institutions in the field of ar chaeology that were most ac tive on Twitter - even bef ore the pa ndemic - not onl $y \mathrm{~d}$ emonstrated t hat they ha $\mathrm{d}$ perfectly as similated the e ducommunicative language, but also, with the health crisis and the forced closure of physical activity, they chose to expand and diversify their content; likewise, institutions $t$ hat had pr eviously $b$ een I ess ac tive on this platform dev eloped $p$ lanned educommunicative activity that was attractive to all audiences.
\end{abstract}

Key words: digital educommunication; archaeological and site museums; social media; Twitter; covid-19.

\footnotetext{
* Navarro-Neri, Universidad d e Z aragoza, G rupo de i nvestigación A RGOS, I UCA, (ORCID 0000-0001-8589-6659); A so, Universidad de Z aragoza, G rupo de i nvestigación A RGOS, I UCA ( ORCID 0000-0002-3023-4516); Me ndioroz-Lacambra, Universidad Pública de Navarra, G rupo de investigación ARGOS (ORCID 0000-0002-7060-7065). Autor de Correspondencia: Navarro-Neri: inakinavarro@unizar.es

Navarro-Neri, I., Aso, B. y Mendioroz-Lacambra. A. (2021). Análisis del lenguaje educomunicativo de los museos arqueológicos españoles dur ante el c onfinamiento de 2020. Clio. History and History Teaching, 47, 132 -160. https://doi.org/10.26754/ojs_clio/clio.2021475522 Recibido 03/06/2021. Aceptado 30/9/2021.
} 


\section{Introducción}

Los museos han sido, sin duda alguna, uno de los sectores más golpeados por la crisis sanitaria de la covid-19. Mientras que el $90 \%$ de estos espacios se vieron obligados a cerrar sus puertas durante la crisis (aproximadamente unas 85.000 instituciones en todo el planeta), se calcula que más del $10 \%$ probablemente nunca vuelvan a abr ir sus puertas nuevamente (UNESCO, 2020). O tros informes cifran las pérdidas en 20.300 eur os semanales durante el co nfinamiento, I o que ha a fectado directamente a I a co ntratación de per sonal y al fin forzoso de co laboraciones con programas de voluntariado (NEMO, 2020).

Los museos cu entan ya co $\mathrm{n}$ un esp acio $\mathrm{p}$ ropio co nsolidado dent ro de I as redes sociales (Ristol, 2018), corroborado cuantitativamente en diferentes estudios a lo largo de I os últimos años (Cordón-Benito y G onzález-González, 2016; Navarro-Neri y Rivero, 2019; Puiggrós-Román et al. 2017). Las instituciones arqueológicas españolas han ido introduciéndose paulatinamente en la web 2.0 (Rivero et al. 2020), incluso podemos afirmar que, hoy en día, las redes sociales son parte fundamental en los planes y estrategias de comunicación de los museos (Caerols-Mateo et al., 2017).

El objetivo de este trabajo ha si do analizar si las instituciones museísticas españolas del ám bito a rqueológico despliegan una co municación en cl ave educativa en I a web 2.0. Es decir, si teniendo en cu enta las limitaciones de espacio ( 280 caracteres por tweet) y el lenguaje propio de esta plataforma (lenguaje directo, uso de imágenes, links, vídeos, etc.), los museos y yacimientos arqueológicos españoles desarrollan un lenguaje educomunicativo o si, por el contrario, se dedican a reproducir el contenido volcado en otras plataformas sin adaptarse a las características propias de Twitter.

\section{Estado de la cuestión}

La educo municación es un ca mpo de est udio interdisciplinar y t ransdisciplinar q ue abarca dos disciplinas históricamente separadas: la educación y la comunicación. Alfabetización mediática, peda gogía de l a co municación o educa ción en $m$ ateria de medios de comunicación es lo que hoy se denomina en el mundo anglosajón media literacy o media education. Una disciplina en constante debate y evolución vinculada a la educación en y mediante los medios de comunicación (Barbas-Coslado, 2012). 
La praxis educomunicativa, ligada a las ideas de Freire o Kaplún, surgió al calor de la escuela nueva y las pedagogías críticas, y que actualmente entroncan con los principios propugnados por la sociodigitalidad: procesos de comunicación horizontales, multimedialidad de I a red, en riquecimiento de l os mensajes, códigos más humanos, sencillos y próximos y una comunicación multidireccional que multiplica los nodos a los que llegar (Maldonado-Esteras, 2017).

La UNESCO, durante la década de los años 70, impulsó diferentes espacios para el debate co $\mathrm{n}$ el ob jetivo de formar a la ci udadanía en el uso de los medios de comunicación. U na déca da desp ués, I a obr a de Morsy (1984), La educación en materia de educación, si ental as bases par al a cr eación del co ncepto educomunicación, foco de i nterés para o rganizaciones, i nvestigadores, gr upos de trabajo, etc. (Barbas-Coslado, 2012).

El término educomunicación integra todos los desarrollos referidos al proceso híbrido en el que la comunicación tiene una finalidad educativa y viceversa (Morsy, 1984). Los elementos comunicativos, configurados bajo el prisma educativo, se presentan como pieza clave en la transmisión de contenidos, habilidades, actitudes, aptitudes y valores (Marta-Lazo y Gabelas, 2016).

En la actualidad se ha configurado un escenario educativo y comunicacional que es, en ci erta $\mathrm{m}$ edida, una $v$ uelta al or igen de I a educo municación basa da en I a emancipación y el em poderamiento (Marta-Lazo et al., 2016). S er ci udadano en I o mediático exige cultivar y educar en I as habilidades necesarias para un uso íntegro y amplio de los medios y tecnologías de la comunicación (Gozálvez y Contreras-Pulido, 2014).

Una de I as metas de la educo municación debe se $r$, sin duda, una nuev a forma de ciudadanía: I a ci udadanía m ediática ( Gozálvez y C ontreras-Pulido, 2014) . U na ciudadanía mediática ya no solo que se informe o movilice a través de las redes, sino que, ade más, pot encie el di álogo si n ba rreras físicas y m entales que l e per mitan afianzar, o incluso hacer evolucionar, su propia identidad, pero, sobre todo, reconocer y valorar la del resto.

Los espacios en la web 2.0 moderados por las instituciones encargadas de la custodia, salvaguarda, i nvestigación y di fusión del pat rimonio ( museos, y acimientos, instituciones culturales de di versa índole, et c.), so n el em plazamiento digital i dóneo 
para: 1 ) permitir a la ciudadanía acceder a una formación en educación patrimonial a lo largo de la vida más allá de las limitaciones de acceso al elemento patrimonial por cuestiones geográficas o incluso económicas; y 2) creemos que un perfil institucional que se muestre ac tivo, di alogante y que I leve a ca bo una educo municación del patrimonio acorde con la plataforma -flexible a los posibles temas de conversación y debate que puedan su rgir en el día a día-, que busque la conexión y el diálogo entre sus seguidores, so $\mathrm{n}$ es pacios propicios para el su rgimiento de ci bercomunidades patrimoniales que aglutinen a personas con inquietudes similares hacia el patrimonio y que, por ejemplo, no solo sean los mejores embajadores del patrimonio si no también los primeros en movilizarse an te si tuaciones de $r$ iesgo co mo de terioro, ex polio o destrucción del patrimonio (Rivero et al., 2020).

En est e se ntido, el di scurso cibernético, co ncepto surgido al ca lor de los primeros debates teóricos sobre ci berperiodismo y estrechamente $r$ elacionado co $\mathrm{nl}$ a educomunicación di gital, est á compuesto po r ci nco ca racterísticas definitorias, multimedialidad, hi pertextualidad, i nteractividad, uni versalidad e i nstantaneidad (Álvarez-Marcos, 2003), las cuales se manifiestan claramente en la web 2.0 -redes sociales-. De ellas, y para nuestro objeto de estudio, nos centramos en el estudio de la red social Twitter. Esta, como el resto de plataformas 2.0, obliga a configurar el discurso como un puzle en donde l a pantalla no es un espacio cerrado de exposición de datos, sino que se trata de un espacio abierto donde el receptor abandona el rol de sujeto pasivo para convertirse en co municador comunicado y em poderado (Alberich, 2005). Twitter ha sido considerado como un "sistema de inteligencia colectiva" (Flores, 2009), una red social donde la interacción y las relaciones que surgen entre los usuarios posibilita el surgimiento de co munidades de aprendizaje colaborativo a partir de la puesta en común y la recomendación de contenidos (Lewis et al., 2010).

Precisamente, por que I a educo municación en la r ed se ha co nvertido en un pi lar fundamental par a el i ntercambio y I a di fusión de co ntenidos desde muy d iversas instituciones (Chiappe y Arias, 2016), plataformas como Twitter son el contexto idóneo para I a cu Itura (Narváez-Montoya, 2019) y I a educación pat rimonial ( Pineiro et al., 2018; Ibáñez-Etxeberria et al., 2020).

El museo vive una evolución constante tanto en lo que respecta al concepto como en lo que se refiere a las funciones que debe asumir. Espacio para las élites, lugar para la conservación...hasta poder considerarse en la actualidad un ág ora donde institución y 
público intercambian pensamientos e ideas (Haller-Baggesen, 2014). Un foro que converge con unos escenarios de la comunicación en perpetuo debate y conflicto entre el ca rácter pa rticipativo y dialógico, se gún I os tecnoutópicos, o un ent orno vigilado excesivamente poblado de usuarios poco participativos para los apocalípticos 3.0 (Marta-Lazo y G abelas, 2016 ). Toda es ta evolución -transformación haci a I a alfabetización digital- posibilita al público conectarse con los conocimientos dentro de entornos de aprendizaje informales, per mitiéndoles convertirse en act ores culturales dinámicos (Russo et al., 2009).

Mientras que autoras como Villaespesa (2018) apuntaban a que las redes sociales eran un esp acio idóneo para aum entar y mejorar el diálogo entre los museos y sus audiencias, otros autores iban más allá recogiendo las posibilidades que ofrece la web 2.0 para la creación de nuevos conocimientos (Suzić et al., 2016). Unos medios sociales que ofrecen al público capacidades para explorar respuestas complejas, que antes no estaban disponibles dentro de los entornos de aprendizaje informales.

No ca be duda de q ue, para ace ptar el rol del museo co mo espacio para establecer nuevas relaciones con el público, inspiradas en un co mpromiso dem ocrático co n el patrimonio cultural, hace falta un compromiso interno con la causa (Haller-Baggesen, 2014). Es decir, para que una institución museística se muestre en la web 2.0 como un espacio de encuentro verdaderamente democrático y conectado con la actualidad es necesario que su personal, además de que esté debidamente formado en el uso de las TIC o en el lenguaje educomunicativo propiamente dicho, asuma también como propia esa i dea de $\mathrm{m}$ useo co mo esp acio de encu entro no so lo en el esp acio físico si no también en el espacio virtual: las redes sociales.

En definitiva, un paso de las TIC (Tecnologías de la Información y de la Comunicación) a las TRIC (Tecnologías para la Relación, Información y Comunicación) (Gabelas et al. 2012) donde esa I no corresponde a una a cumulación de dat os y contenidos inútiles, sino que debe ser un facilitador para alcanzar la interacción e inmersión del usuario y así, co nvertido en i ndividuo co nectado, en i nteligencia co lectiva, formar par te del conocimiento (Gabelas y Marta-Lazo, 2020).

La educomunicación del patrimonio, en especial en la web 2.0, se ubica bajo el paraguas de lo que actualmente se denomina como educación patrimonial. Aunque el concepto "educación patrimonial" es relativamente amplio y nuevo -todavía en muchos 
programas educativos se sigue hablando de pe dagogía del patrimonio o de didáctica del patrimonio-, sus primeros pasos en España se remontan al año 2003 a partir de referentes tomados de la didáctica del patrimonio y museum studies (Rivero et al., 2020). Tras más de una década de producción científica, la educación patrimonial ya puede se $r$ considerada co mo una di sciplina aca démico-científica " emergida" y consolidada (Fontal e Ibáñez-Etxeberria, 2017).

En I a úl tima déca da se han incrementado significativamente el número de investigaciones centradas en el uso de las redes sociales por parte de las instituciones culturales. En España, por ejemplo, se pueden destacar investigaciones como las de Gómez-Vílchez ( 2012), Claes y Deltell (2014, 2019), Cordón-Benito y GonzálezGonzález (2016) o Viñarás-Abad y Caerols-Mateo (2016), entre otros.

A nivel internacional, también son ya numerosas las investigaciones en este ámbito y que, co mo en el ca so esp añol, si guen est rategias metodológicas y $t$ emporales diferentes en cuanto al anál isis de ca mpañas concretas o est rategias globales. Por citar algunas, en el caso estadounidense destacan las investigaciones de Garner et al. (2016) y la de Fletcher y Lee (2012). En Dinamarca, Holdgaard y Ekelund-Simonsen (2011) y Trolle-Gronemann et al. (2015) han analizado la posición con respecto al uso de las TIC y las redes sociales como Facebook de los museos daneses. O en el caso de $\mathrm{G}$ ran $\mathrm{B}$ retaña, co $\mathrm{n}$ aut ores co mo K idd (2011), so bre I a ca pacidad de I as instituciones museísticas para generar engagement a través de las redes sociales, o Samaroudi et al. (2020), que analizaron las estrategias desarrolladas por los museos británicos y estadounidenses durante la crisis de la covid-19.

En la actualidad más reciente, las redes sociales presentan cada vez más formas de consumir productos culturales en espacios como los museos (Fernández et al., 2020), tratándose de un medio para la construcción de la realidad so ciocultural y también como he rramienta de mediatización del pat rimonio hi stórico y cu ltural ( Myna et al., 2020).

Este estudio se enmarca dentro de una línea de trabajo iniciada hace ya más de diez años sobre el papel de I as instituciones culturales en I as redes sociales (Claes y Deltell, 2014, 2019; Gómez-Vílchez, 2012; Martínez-Sanz, 2012) y que en España ha dado I ugar a nu merosas tesis doctorales (Aso, 2021 ; LI erena-lglesias, 2016; Maldonado-Esteras, 2015). 


\section{Metodología}

El enf oque metodológico de est a investigación se basa en la genealogía didácticocontextual est ablecida por C alaf et al. (2015) y en l os procesos de interpretación, comunicación y difusión del patrimonio (Kitungulu, 2015; Martín-Cáceres y CuencaLópez, 2015).

El obj etivo principal d e la investigación anteriormente $r$ ecogido, analizar si las instituciones museísticas españolas del ámbito arqueológico despliegan una comunicación en clave educativa en la web 2.0, se ope rativiza en tres objetivos específicos: OE1. cuantificar la actividad en Twitter a partir de los hashtags educativos más utilizados por los museos y y acimientos arqueológicos durante el per iodo del estado de alarma y su evolución durante los diez meses posteriores; OE2. analizar los tipos de códigos, combinaciones y la función del lenguaje predominante de cada post que contenga el hashtag más utilizado por los museos arqueológicos españoles más activos durante el periodo del estado de alarma. Y, por último, OE3. identificar las propuestas más interesantes desde el punto de vista educomunicativo diseñadas por los museos y yacimientos arqueológicos españoles durante el periodo del estado de alarma.

Para ello, se ha analizado la actividad en Twitter entre los meses de marzo y junio de 2020 atendiendo a una serie de categorías de análisis como son: el número de seguidores, la actividad total y la cantidad de tweets propios -tweets emitidos por la propia i nstitución si n co ntar retweets o co ntenido co mpartido- contabilizada por I a herramienta diseñada por Gabás (2019), repitiéndose el mismo proceso en mayo de 2021 para poder cuantificar así el crecimiento en cuanto a número de seguidores y de actividad llevada a cabo por los museos arqueológicos y "de sitio" españoles en los últimos diez meses (OE1). Para la consecución de los objetivos específicos 2 y 3 se empleó, co n una se rie de adapt aciones, el i nstrumento de anál isis IA-EduComR [véase Instrumento de análisis en redes sociales (IA-EduComR)] y e I enf oque investigativo de estudio de casos, destacando las propuestas educomunicativas más significativas de I os museos analizados resultantes del tercer filtro de se lección y cribado de la muestra. 


\section{Muestra}

Los museos arqueológicos representan una de las categorías museísticas con más recursos digitales: $r$ ealidad aum entada, $r$ ealidad $v$ irtual, $r$ econstrucciones $o v$ isitas virtuales (Ibáñez-Etxeberria et al., 2020; Ibáñez-Etxeberria et al., 2014). La muestra de este estudio se conforma a partir de los perfiles catalogados en el Directorio de Museos y Colecciones de España, dependiente del Ministerio de Cultura y Deporte del Gobierno del Reino de España. Para el primer filtrado de la muestra, los criterios de búsqueda fueron por temática, introduciendo los descriptores predefinidos por el sitio web: "arqueológico" y "de sitio". Este primer criterio de selección arrojó un resultado de $\mathrm{N}=254$ instituciones.

El siguiente filtro fue localizar los perfiles oficiales en Twitter de las 254 instituciones. Esto redujo la se lección a 59 p erfiles autodenominados como perfiles oficiales de la institución. Esta cifra representa un $23,2 \%$ de I as 254 instituciones catalogadas bajo las etiquetas "arqueológico" y "de sitio".

El tercer filtro de se lección fue co nocer el flujo de act ividad de las 59 instituciones localizadas en la red social. Solo $n=31$ instituciones registraban en su perfil al menos un ejemplo de una actividad reseñable como constante y planificada. Este criterio se estableció bajo un mínimo de cantidad y periodicidad: de 3 a 5 tweets semanales con contenido propio. Tan solo un $12,2 \%$ de todas las instituciones españolas catalogadas desde el Ministerio bajo las etiquetas "arqueológico" y "museo de sitio" cuentan con un perfil oficial en Twitter y su actividad puede catalogarse como planificada, constante y, por tanto, potencialmente interesante en términos educomunicativos.

Finalmente, de la muestra depurada, se efectuó un est udio de ca sos donde el objeto de análisis ha sido llevado a cabo únicamente en aquellos hashtags promovidos por las instituciones que hubiesen sido utilizados en, al menos, 40 tweets. Esta medida de tweets presupone un a g estión co nstante del hashtag pues su ut ilización aproximadamente debería ser de ent re tres a cinco veces por semana. Además, este volumen nos permite hablar de un pr oceso e ducomunicativo g lobal (un hashtag utilizado co $n$ asi duidad), I ocalizable en I a apl icación ut ilizando I as herramientas de búsqueda y que hac e posible t ambién I ocalizar y anal izar l a r espuesta del públ ico durante un periodo de tiempo más allá de las acciones puntuales tan utilizadas en la Web 2.0 (Gabás, 2019). 
En definitiva, la muestra está conformada por aquellos espacios que llevan a cabo una actividad en Twitter constante y que, al menos, pueda parecer enmarcada dentro de un plan de comunicación. Teniendo en cuenta el volumen de contenido y la inmediatez en las interacciones que Twitter permite, se consideró que, una institución que verdaderamente pl anifique su a ctividad en est a plataforma, co mpartiría el contenido educativo utilizando un hashtag original o tomado de otras iniciativas (\#MuseumWeek, \#Askacurator...) co no tros usuarios con l as m ismas inquietudes, así co mol a localización posterior mediante la herramienta de búsqueda de la propia aplicación.

Población total: identificación

Monitorización: búsqueda de perfiles oficiales en Twitter

Selección muestra: perfiles con actividad constante (3-5 tweets/semana)
Museos "Arqueológicos" (n=208) y "de sitio" (n=46) españoles. Población total: $\mathrm{N}=254$

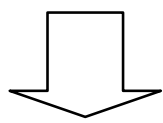

Museos "Arqueológicos" y "de sitio" españoles con perfil oficial en Twitter: $n=59$ (23,2\%)

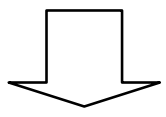

Museos "Arqueológicos" y "de sitio" españoles con perfil oficial en Twitter y actividad constante: $n=31$ (12,2\%)

Figura 1: Diagrama de flujo sobre el filtrado de la muestra

\section{Instrumento de análisis de la educomunicación en redes sociales (IA-EduComR)}

En el desarrollo de esta investigación se han empleado dos herramientas/instrumentos de anál isis de la actividad en Twitter, uno de c orte cu antitativo y ot ro basa do en el análisis de contenido del discurso -cualitativo-. Por un Iado, y para responder al OE1, se ha utilizado una herramienta de análisis mediante métricas de la actividad en redes sociales, concretamente en Twitter, elaborada por Gabás (2019). Esta herramienta nos permite dejar constancia de $\mathrm{I}$ a actividad en ci fras, en $\mathrm{m}$ uchos casos incluso totales, desde la fecha de creación de la cuenta, lo que nos posibilita inferir inmediatamente perfiles institucionales poco activos en esta plataforma. 
Por otro lado, y en relación con el OE2, se ha partido del instrumento de análisis IAEduComR desarrollado y ut ilizado par a anal izar l a act ividad en Twitter durante los meses de m arzo a j unio del año 2020 de l os museos arqueológicos y de si tio españoles e i talianos (García-Ceballos et al ., 2021; Rivero et al ., 2020). A grandes rasgos, su desa rrollo teórico puede enco ntrarse en I os artículos antes mencionados, se analizó el uso por parte de estas instituciones de la secuencia procedimental para la educación patrimonial (Fontal, 2003), el factor R-elacional formulado recientemente en varios estudios (Marta-Lazo y Gabelas, 2016; Marta-Lazo et al., 2016) y el tipo de aprendizaje dom inante que puede $p$ roducirse a par tir de I a propuesta de Siemens (2005). Además, se tomaron como referentes algunos artículos que recogen claves o factores integrados en la teoría de la educomunicación del patrimonio (Calaf et al., 2015; Ibáñez-Etxeberria et al., 2020; Martín-Cáceres y Cuenca-López, 2015).

El i nstrumento de análisis IA-EduComR $r$ ecogido $m$ ás arriba se ha co mpletado añadiendo dos nuevas variables (tabla 1) que van a permitir ahondar en el estudio y medición de la educomunicación digital: por un lado, la multimedialidad empleada por las instituciones, par tiendo de l a de finición p ropuesta desd e el á mbito per iodístico, como "la utilización conjunta de las formas básicas de información, es decir, texto, sonido, i magen fija y ani mada, en un mismo entorno, y de manera y uxtapuesta o integrada" (Abadal y Guallar, 2010, p. 42), utilizada en ca da Tweet por parte de I as instituciones museísticas. En esta variable 1 se han recogido las combinaciones más utilizadas que permite la plataforma dando como resultado nueve indicadores que van, por ejemplo, desde el uso exclusivo de un recurso como el texto (1.1), la imagen (1.3) o el vídeo (1.6) hasta la combinación de texto e imagen (1.4), texto y URL (1.2) o combinaciones más complejas con tres o más elementos (1.5 y 1.8) (ver anexos: tabla 3).

$\mathrm{Y}$, por ot ro, I a función del I enguaje $\mathrm{p}$ redominante a par tir de I as propuestas desarrolladas por Eguren-Gutiérrez (1987) y Jakobson (1984), con el fin de completar el análisis educomunicativo siguiendo la definición surgida en el Seminario Latinoamericano de 1991 organizado por la CENECA en Chile y que recogía Aparici (2010, p . 9): "[...] la ed ucomunicación incluye, sin reducirse, el co nocimiento de I os múltiples lenguajes y medios por los que se realiza la comunicación personal, grupal y social. A barca t ambién I a f ormación del se ntido cr ítico, i nteligente, frente a I os 
procesos comunicativos y sus mensajes para descubrir los valores culturales propios y la verdad".

\begin{tabular}{|c|c|c|}
\hline Variables & Indicadores & Descriptores \\
\hline \multirow{10}{*}{$\begin{array}{l}\text { 1. Multimedialidad: } \\
\text { tipos de códigos y } \\
\text { combinaciones }\end{array}$} & 1.1 Solo texto & $\begin{array}{l}\text { Texto propio, respuesta, retweet } \\
\text { sin imágenes }\end{array}$ \\
\hline & $\begin{array}{l}1.2 \text { Texto y URL del museo o } \\
\text { externa }\end{array}$ & $\begin{array}{l}\text { Texto y un enlace propio del } \\
\text { museo o a otra web }\end{array}$ \\
\hline & 1.3 Solo imagen & $\begin{array}{l}\text { Solo una imagen sin texto } \\
\text { explicativo }\end{array}$ \\
\hline & 1.4 Texto e imagen & $\begin{array}{l}\text { Texto e imagen sin url u otros } \\
\text { contenidos }\end{array}$ \\
\hline & $\begin{array}{l}1.5 \text { Texto, imagen y Url del } \\
\text { museo o externa }\end{array}$ & $\begin{array}{l}\text { Texto, imagen y una url a } \\
\text { contenido del museo o externo }\end{array}$ \\
\hline & $\begin{array}{l}\text { 1.6 Vídeo integrado en Twitter } \\
\text { sin texto }\end{array}$ & $\begin{array}{l}\text { Vídeo subido en Twitter sin texto } \\
\text { explicativo }\end{array}$ \\
\hline & $\begin{array}{l}1.7 \text { Texto y vídeo integrado en } \\
\text { Twitter }\end{array}$ & Texto y vídeo integrado en Twitter \\
\hline & $\begin{array}{l}\text { 1.8 Texto, vídeo integrado en } \\
\text { Twitter y url del museo o externa }\end{array}$ & $\begin{array}{l}\text { Texto, vídeo integrado en Twitter y } \\
\text { URL del museo o externa }\end{array}$ \\
\hline & $\begin{array}{l}1.9 \text { Encuesta (pregunta y se } \\
\text { puede seleccionar una o varias } \\
\text { opciones) }\end{array}$ & $\begin{array}{l}\text { Pregunta con varias respuestas } \\
\text { entre las que elegir }\end{array}$ \\
\hline & Otros & Ninguna de las anteriores \\
\hline \multirow{5}{*}{$\begin{array}{l}\text { 2.Funciones del } \\
\text { lenguaje } \\
\text { predominantes }\end{array}$} & 2.1 Expresiva/emotiva & $\begin{array}{l}\text { El emisor expresa sentimientos, } \\
\text { utiliza la primera persona }\end{array}$ \\
\hline & 2.2 Apelativa/conativa & $\begin{array}{l}\text { Se intenta llamar la atención del } \\
\text { receptor, interpelaciones, uso de } \\
\text { la } 2^{\mathrm{a}} \text { persona... }\end{array}$ \\
\hline & 2.3 Referencial/representativa & Discurso academicista \\
\hline & 2.4 Poética & $\begin{array}{l}\text { Se busca la belleza usando } \\
\text { poemas, metáforas... }\end{array}$ \\
\hline & 2.5 Lúdica & Chistes, uso de memes, viñetas. \\
\hline
\end{tabular}

Tabla 1: Instrumento de análisis de la educomunicación en redes sociales 


\section{Resultados}

\section{Los museos arqueológicos y de sitio españoles en cifras}

En primer lugar, tomando como punto de partida los datos obtenidos en el análisis de julio de 2020 ( Rivero et al., 2020 ) y que post eriormente fueron comparados con los datos obtenidos por I os museos ar queológicos italianos para I as mismas fechas (García-Ceballos et al., 2021), se ha realizado una nueva observación en cuanto a los indicadores antes señalados con fecha de mayo 2021 (ver anexo: tabla 2).

Los resultados obtenidos muestran dos casos muy l lamativos por el aum ento en el número de se guidores y l a act ividad I levada a ca bo: en $\mathrm{p}$ rimer I ugar, el $\mathrm{M}$ useo Nacional de Arqueología Subacuática (en adelante ARQVA) ha duplicado su número de seguidores (un aumento del $125,8 \%$, pasando de 1.510 seguidores a 3.409 ) y ha comenzado una política educomunicativa constante y planificada con tweets diarios de carácter predominantemente informativo ( $76,3 \%$ de crecimiento en I a actividad total y un $72,6 \%$ más de actividad propia, es decir, de tweets con contenido escrito por el propio museo).

Por su pa rte, el se gundo ca so a des tacar po r su c recimiento en el núm ero de seguidores es el del yacimiento ar queológico de Li bisosa ( Albacete, C astilla I a Mancha), el cual, partiendo de unas cifras bastante reducidas, ha conseguido duplicar el número de seguidores en estos meses (crecimiento del 107,3\%), con un interesante aumento porcentual en la actividad diaria $(69,7 \%$ en cuanto al crecimiento total y un $58,2 \%$ de aumento en el número de tweets originales).

El tercer caso es el del Conjunto Arqueológico Sitio de los dólmenes de Antequera (en adelante dól menes de Antequera), donde v emos un c recimiento por centual en el número de se guidores considerable $(43,4 \%)$, p ero so bre todo una mayor act ividad diaria (crecimiento total del $87,4 \%$ ) y una mayor ac tividad propia (tweets originales) (33,7\% de crecimiento).

En el resto de instituciones el incremento de seguidores se sitúa entre un $10 \%$ y un $20 \%$. En lo que respecta a I a act ividad, ca be destacar que prácticamente todas las instituciones han aumentado considerablemente su actividad propia en mayor medida que I a act ividad t otal, I o q ue co nstata I a exi stencia de una po lítica c omunicativa constante. 


\section{Lenguaje educomunicativo y función del lenguaje predominante}

Agrupar los posts publicados por los museos arqueológicos y de sitio españoles nos permite cuantificar no solo la variedad de recursos que utilizan estas instituciones para generar y compartir contenido educativo, sino también para comprobar si, tras cincodiez años de media de presencia en esta plataforma, dominan el lenguaje propio de esta red social: contenido claro y conciso por las limitaciones de espacio (280 caracteres por tweet), el uso de imágenes, links, etc.

En primer lugar, de staca que el $43,4 \%$ de t odas las publicaciones analizadas (1177 posts) están compuestas por texto e imagen. Un tipo de multimedialidad que es mayoritaria en todos los museos analizados salvo en tres casos: i) el MARQ, que llevó a ca bo una apuest a de cidida por el uso del ví deo donde un $\mathrm{m}$ iembro del $\mathrm{m}$ useo explicaba su obra favorita o al gún elemento de la colección (85 tweets); ii) el MNAR, donde se optó principalmente por compartir únicamente imágenes (33 tweets), ya que el texto explicativo estaba en el propio contenido de I a imagen; iii) y la Alcazaba de Almería, donde el $\mathrm{t}$ ipo de tweet mayoritario fue el co mpuesto por i magen, texto explicativo y un link para ampliar la información (172 tweets).

Las cifras más significativas, por la variedad en sus propuestas, son las obtenidas por la Alcazaba de Almería y el Museo Arqueológico Nacional. En el caso de la Alcazaba de Almería, los datos resultantes constatan la variada programación que llevó a cabo esta institución: posts con texto e imagen (156 tweets) de carácter divulgativo, reivindicativo, emotivos... como puede constatarse en los indicadores obtenido en la tabla 4 ( 3.4 y 3.5). A demás, su pr opuesta t itulada \#T rivialAlcazabeño ut ilizando la herramienta "encuesta" (91 tweets) de la propia plataforma fue una de I as actividades más seguidas por el público.

El Museo A rqueológico Nacional viene mostrando en I os últimos años una deci dida apuesta por la educo municación a t ravés de la plataforma so cial Twitter. Durante el estado de alarma combinó el uso de tweets compuestos por texto e imagen ( 61 tweets), normalmente para explicar alguna pieza de la colección, con un tipo de publicación compuesta por texto, imagen y URL del propio museo (50 publicaciones), lo que le ha pe rmitido conectar el contenido de su web oficial con sus seguidores en redes sociales. 
La función del I enguaje pr edominante en est as publicaciones ha si do I a referencial/representativa ( $65 \%$ de I os 1177 tweets analizados). C abe dest acar de nuevo el caso de la Alcazaba de Almería, que además de su prolífica actividad en la red social (más de 4 tweets diarios de media) destaca por ser una institución que no se ha q uedado ancl ado al m ensaje institucional ( $212 \mathrm{t}$ weets), si no que ha co mbinado estos con otros de carácter expresivo/emotivo, apelando a los sentimientos o utilizando la primera persona (148 tweets) y, en menor medida, mensajes de carácter apelativo/conativo ( 76 tweets), I igados lógicamente a $t$ odas I as propuestas participativas que lanzó la institución.

\section{Contenido y estrategias educomunicativas}

Aunque se han anal izado con I a her ramienta I A-EduComAR todos I os hashtags empleados con fines educativos por cada una de las instituciones mencionadas en la muestra; en este caso, si guiendo en par te la metodología propuesta por el OEPE (Fontal y Juanola, 2015) de estudios de caso que resulten significativos para el ámbito de I a educa ción pat rimonial, hay q ue des tacar so bre el $r$ esto de i nstituciones la actividad llevada a cabo por la Alcazaba de Almería, no solo por sus cifras en cuanto a cantidad de publicaciones diarias, sino también por la calidad y variedad de sus propuestas. También destacaron otras instituciones ya con un largo recorrido en la web 2.0, como el Museo Arqueológico Nacional o el MARQ (ver anexo: tabla 4).

Muy por encima de la actividad llevada a cabo por los otros espacios que componen la muestra, I a A Icazaba de A Imería f ue I a i nstitución m ás productiva ( 461 tweets localizados a través del hashtag \#TuAlcazabaOnLine o \#A IcazabaOnline) y co n el contenido más variado: tweets dedicados a divulgar diferentes aspectos de la alcazaba como eventos pasados, otros apelando a que sus seguidores compartiesen su mejor foto en I a al cazaba u ot ros facilitando material di dáctico dedicado al público infantil. Los anteriores son solo algunos ejemplos de una actividad constante (4/5 tweets diarios) que, si bien ya venía siendo en términos educomunicativos atractiva, variada y planificada, con el ci erre forzoso de I a act ividad pr esencial, I a i nstitución opt ó po $r$ ampliar el contenido y también por recuperar algunos hashtags participativos como \#TrivialAlcazabeño u ot ros de ca rácter di vulgativo co mo \#C erradoporexcavación, mejorando sobremanera la experiencia del usuario en Twitter. 
Por su par te, el $\mathrm{M}$ useo Arqueológico $\mathrm{N}$ acional at ravés del hashtag \#MANSiempreCerca llevó a cabo una actividad constante y variada: la institución volvió a co mpartir contenidos como reproducciones en $360^{\circ} \mathrm{o}$ an tiguas conferencias colgadas en el canal oficial del museo en YouTube, añadiendo el hashtag creado para el periodo del estado de alarma.

Por otra parte, una de I as apuestas más interesantes por su formato fue la llevada a cabo por el MARQ de Alicante, quien optó por una rutina de publicaciones compuestas por texto y vídeo. En estas publicaciones el texto servía como excusa para presentar un ví deo donde un $\mathrm{m}$ iembro del per sonal de la i nstitución $\mathrm{r}$ evelaba de $\mathrm{m}$ anera argumentada su obra favorita o recorría al gún punto del museo explicando una pi eza concreta.

El Museo Nacional de Arte Romano, hasta entonces prácticamente inactivo en Twitter, optó por una est rategia basada en propuestas "R-elacionales" utilizando los hashtags \#EnCasaconeIMNAR y/o \#LaCulturaentuCasa. Actividades participativas como "cocina como un r omano", don de l a i nstitución co mpartía r ecetas de co cina de I a ant igua Roma pi diendo a su s seguidores que compartiesen I os resultados; I a recreación de escenas e imágenes utilizando figuras de Playmobil o una propuesta para el público infantil de $r$ ecreación d e dei dades del O limpo, si guiendo unas plantillas colgadas también en la web oficial, utilizando elementos cotidianos disponibles en la mayoría de los hogares. Una actividad que se complementaba con una imagen a modo de ejemplo y con un pequeño texto con 4-5 ideas descriptivas.

\section{Discusión}

De acuerdo con estudios anteriores (García-Ceballos et al., 2021; Navarro-Neri y Rivero, 2019; R ivero et al ., 2020 ), I o primero q ue I lama I a at ención es el baj o porcentaje de museos con perfil oficial en Twitter. En España, siguiendo el Directorio de Museos y Colecciones de España, hay 254 i nstituciones catalogadas bajo I a etiqueta "arqueológico" y/o "de sitio". Apenas 59 instituciones cuentan con un perfil oficial en Twitter; de he cho, tan solo un 23, 2\% de los museos "arqueológicos" y "de sitio" españoles están en esta plataforma. Datos muy similares a los que arrojaban los Museos Navales y Marítimos del ámbito hispanohablante en 2015, donde de las 114 
instituciones, tan so lo el $40 \%$ t enía presencia en las redes sociales y de el las, 18 museos contaban con perfil oficial en Twitter (15,8\%) (Díaz-Pérez et al., 2015).

Por otra parte, atendiendo al informe elaborado por el ICOM a partir de los resultados obtenidos en una investigación realizada entre septiembre y octubre de 2020, se señalaba que, en comparación con el mismo estudio llevado a cabo en abril de 2020 , los museos seguían mejorando sus actividades digitales (ICOM, 2020). Es decir, los museos no solo ace ptaron el desafío de g enerar rápidamente materiales didácticos para compartir en su web of icial y en I a web 2.0, sino que, además, el paso de I os meses y una mejor planificación les permitió aumentar todavía más su apuesta por el contexto de aprendizaje en red.

Los resultados obtenidos en esta investigación refrendan esta afirmación si ponemos el foco en las instituciones destacadas en el apartado de análisis de resultados: museos como el ARQVA, Libisosa o los Dólmenes de Antequera son tres ejemplos de instituciones que tras los primeros meses de crisis sanitaria aumentaron su actividad en Twitter significativamente. Estas instituciones se suman a la lista de museos activos en est a plataforma que encabezan el Museo Arqueológico Nacional, Ia A lcazaba de Almería o el Museo de la Evolución Humana, entre otros.

Algunos informes elaborados durante el úl timo año -como el e laborado por NEMO (2020)- señalan cómo el 70\% de los museos analizados incrementaron su presencia online durante el mes de marzo, llegando al $80 \%$ en el mes de abr il. Este en foque forzoso hacia una ac tividad casi exclusivamente onl ine provocó que el $21,8 \%$ de los museos tuviese personal dedicado a tiempo completo a esta actividad, llegando hasta el $56,8 \%$ en el caso de museos con personal dedicado al contenido digital pero no a tiempo completo (ICOM, 2020).

Este not able es fuerzo ant e I a cr isis sanitaria de I a covid-19 por parte de I as instituciones museísticas ha $v$ enido a $r$ eforzar el ca mino i niciado en 2015 po $r$ UNESCO, quien en su informe "UNESCO Recommendation concerning the Protection and Promotion of Museums and Collections, their Diversity and their Role in Society" no so lo su brayaba l o e sencial del $r$ ol dese mpeñado por los museos en el ám bito cultural, sino su importancia también tanto para ser un motor de progreso y bienestar 
social desde una dimensión educativa como en la potenciación del uso de las Tecnologías de la Información y Comunicación (UNESCO, 2020).

Si consideramos el periodo analizado como "acción puntual", entendida esta como la acción educo municativa I levada a ca bo por I a i nstitución en un per iodo t emporal concreto $\mathrm{c}$ on una $\mathrm{m}$ otivación esp ecífica (\#MuseumWeek, \#Askacurator o \#ColorOurCollections), la estrategia educomunicativa desplegada por los museos españoles puede ser comparable con las analizadas en otras investigaciones (Garner et al ., 2016; Zuanni , 2017). E n el ca so i taliano, ca be des tacar que I as pocas instituciones activas durante el periodo del estado de alarma (García-Ceballos et al., 2021) apenas optaron p or Twitter, focalizando su producción co municativa en I a red social Facebook, donde ya venían realizando una actividad educomunicativa constante y planificada (Zuanni, 2017).

La mayoría de instituciones analizadas utilizan un lenguaje educo municativo basa do en una m ultimedialidad compuesta preferentemente por el texto y la imagen (43,4\%). Se trata de una es trategia en consonancia con el ritmo frenético imperante en la web 2.0, que hace que la imagen sea la forma más sencilla de ex plicar cualquier idea o concepto de manera más directa, sencilla y, sobre todo, rápida (Marcelino-Mercedes y de la Morena-Taboada, 2014). Le sigue el empleo del texto, imagen y URL $(24,1 \%)$. Estos datos están en la línea del trabajo de Díaz-Pérez et al. (2015) sobre la actividad en Facebook y Twitter de los Museos Navales y Marítimos (57,7\% en el caso de los museos españoles y el $49 \%$ en los museos latinoamericanos), quedando muy lejos el resto de tipologías como solo texto (15,5\% y $29,5 \%$ respectivamente) o texto e imagen $(19 \%$ y $8,3 \%)$. No obs tante, al no I levar a ca bo un anál isis del di scurso de est as instituciones no podemos asumir que la causa de estos porcentajes esté motivada por el em pleo de un contenido textual predominantemente informativo y/o publicitario o que no hubiese una estrategia educomunicativa diseñada previamente por las instituciones.

No obstante, en el estudio realizado en 2016 por Cordón-Benito y González-González donde se anal izaba la actividad durante un mes en Twitter del Museo del Prado, el Museo Reina Sofía y el Museo Thyssen, se constató que el tipo de publicación más utilizado f ue el uso exclusivo del t exto: co mpartir co ntenidos de ot ros m ediante la herramienta retweet o respondiendo a interacciones con otros usuarios e instituciones 
(Cordón-Benito y González-González, 2016). En este se ntido, no se puede I levar a cabo una comparación cuantitativa al uso ya que en el caso de la investigación que se expone en est e ar tículo úni camente se han an alizado I as propuestas directamente elaboradas por las instituciones, descartando el contenido que hayan podido compartir de otros durante este tiempo.

Sin embargo, sí que resulta llamativo observar cómo predomina antes una estrategia basada en compartir contenido de ot ras instituciones o usuarios, que una basa da en la creación de co ntenido or iginal y propio, lo que nos hace suponer que en 2016 el contenido en I a web 2.0 no er a una pr ioridad para estas instituciones como sí lo es ahora en 2020 -2021, momento en el que I as tres instituciones reseñadas -Museo Nacional C entro de Arte R eina S ofía, Museo Nacional del Prado y Museo Nacional Thyssen-Bornemisza- están implementando una política educomunicativa ejemplar, a la al tura de i nstituciones siempre pun teras en este ám bito co mo el Rijksmuseum de Ámsterdam, la National Gallery de Londr es o el MoMA de N ueva York (MaldonadoEsteras, 2015).

Las iniciativas destacadas en el apartado anterior por resultar ser atractivas y bien planificadas, pese al contexto de urgencia, corroboran las reflexiones surgidas de otras iniciativas como \#ColorOurCollections, Ilevada a cabo principalmente por bibliotecas y algún museo norteamericano y británico. En ella, sus protagonistas (el personal de las instituciones que llevó a ca bo la iniciativa) hablaban de unos objetivos principalmente promocionales, per o también de i nterconexiones entre instituciones. L os resultados obtenidos les permitieron co ncluir q ue una est rategia educo municativa co laborativa que ofrezca flexibilidad y libertad a la hora de publicar, mejora la calidad y la cantidad de participación (Garner et al., 2016).

Un análisis similar en E spaña, en est e caso sobre la actividad llevada a cabo por los museos en el Día Nacional de los Museos y Noche de los Museos, concluía que las instituciones analizadas necesitaban mejorar el diseño y ejecución de sus campañas digitales además de l levar a ca bo una act ividad basa da en c ompartir y no $t$ anto en informar y difundir. Además, también ponían de relieve la desigual implicación de los museos (Caerols-Mateo et al., 2017). 
Los resultados obtenidos en este estudio apuntan a esa desigual participación bien por falta de interés en llevar a cabo una actividad diaria y planificada en Twitter o bien por otros motivos que deberán ser analizados en futuros estudios. Por otra parte, sí podemos hablar de una evolución en la estrategia educomunicativa de los museos, ya que los datos muestran que sí ha habido una planificación más o menos espontánea al llevar a cabo una rutina con un hashtag concreto y, sobre todo, al plantear una educomunicación di versa en cu anto al I enguaje $u$ tilizado y a I os contenidos compartidos.

\section{Conclusiones}

Retomando el objetivo principal, si tenemos en cuenta los datos obtenidos en el análisis del lenguaje educo municativo, I as funciones del lenguaje predominantes en cada ca so y el aná lisis cu alitativo a par tir de un enf oque referido a I a educa ción patrimonial, a las propuestas o ausencia de las mismas de actividades R-elacionales y de la propuesta de aprendizaje predominante, podemos concluir que, si bien falta una apuesta deci dida por experiencias más participativas o $\mathrm{v}$ ariadas en cu anto a I a estructura del contenido (queda constatado el uso excesivo del formato texto e imagen o t exto, i magen y link), los museos ar queológicos y de si tio esp añoles dominan el lenguaje educomunicativo propio de la plataforma Twitter, caracterizado por la limitación de espacio (280 caracteres) y el ritmo vertiginoso de su flujo comunicativo.

En definitiva, si comparamos los datos analizados en esta investigación con algunas de las publicaciones con metodologías similares utilizadas (Caerols-Mateo et al., 2017; Cordón-Benito y González-González, 2016; Díaz-Pérez et al., 2015), siempre teniendo en cuenta todas las limitaciones que es te tipo de comparaciones suponen -diferente marco t emporal, t ipología de $\mathrm{m}$ useo, et c.-, no cabe duda de que l as instituciones museísticas españolas pertenecientes al ámbito arqueológico más activas en Twitter emplean de manera apropiada el lenguaje educomunicativo. A pesar de la situación sanitaria so brevenida, han am pliado su propuesta en $r$ edes sociales adaptándose al lenguaje y códigos del medio empleado. Futuras investigaciones deberán comprobar si esta t endencia ha si do pasa jera o $r$ esponde a un dese o r eal de ca mbio en I as prácticas educomunicativas en red por parte de los espacios museísticos. 
Teniendo en cuenta que algunos de los informes surgidos durante el último año señalan q ue el $74,8 \%$ de I as instituciones están co nsiderando aum entar su o ferta digital o que el 76,6\% está pensando en rediseñar la estrategia digital (ICOM, 2020), futuros estudios de corte longitudinal o enfocados a medir campañas concretas -como \#MuseumWeek o "La Noche de los Museos"- podrán utilizar el instrumento de análisis propuesto en es te estudio y co mparar si, e fectivamente, I as est rategias educomunicativas en la web 2.0 planificadas, diseñadas y atractivas para el público han sido fruto de un co ntexto pasajero o realmente se va a apost ar por ello como se hizo por ejemplo con el contenido en la web 1.0.

\section{Agradecimientos}

Este t rabajo ha si do realizado gracias al pr oyecto E DU2016-78163-R "Educomunicación web 2.0 del patrimonio" (MINECO/AEI-FEDER/UE) y al Grupo de investigación ARGOS (S50_20R), Gobierno de A ragón y FEDER (UE) “Construyendo Europa desde Aragón", 2014-2020.

\section{Referencias}

Abadal, E. y Guallar, J. (2010). Prensa digital y bibliotecas. Trea.

Alberich, J . (2005). Notas para una estética audiovisual di gital. E n A lberich, J . y R oig, A . (Coords.), Comunicación audiovisual digital. Nuevos medios, nuevos usos, nuevas formas (pp. 209-226). UOC.

Álvarez-Marcos J . (2003). EI Periodismo ant e l a tecnología hipertextual. En Díaz N oci, J . y Salaverría R . ( Coords.) Manual de redacción ciberperiodística (pp.231-260). Ariel Comunicación.

Aparici, R. (Coord.). (2010). Educomunicación: más allá del 2.0. Gedisa

Aso, B. (2021). Educación patrimonial en tiempos digitales. Estudio de la educomunicación en redes $\mathrm{S}$ ociales del $\mathrm{M}$ useo $\mathrm{D}$ iocesano de $\mathrm{J}$ aca. [ Tesis doc toral, $\mathrm{U}$ niversidad de Zaragoza].

Barbas-Coslado, Á. (2012). E ducomunicación: desarrollo, e nfoques y desafíos en un m undo interconectado. Foro de Educación, 10(14),157-175. https://www.forodeeducacion.com/ojs/index.php/fde/article/view/22

Caerols-Mateo, R.; Viñarás-Abad, M. y Gonzálvez-Valles, J. E. (2017). Redes sociales y museos: Análisis de la campaña en Twitter para el Día Internacional de los Museos y Noche d el os Mus eos. Rev. Lat. Comun. Soc. 72, 220 -234. http://www.redalyc.org/articulo.oa?id=81952828012 
Calaf, R., G illate, I. y G utiérrez, S. (2015). Transitando p or Ia Evaluación de los Programas Educativos de Museos de Arte del Proyecto ECPEME. Educatio Siglo XXI, 33, 129-50. https://10.6018///222531

Chiappe, A. y Arias, V. (2016). La educomunicación en entornos digitales: un análisis desde los intercambios de información. Opción, 32(7). 461-479. https://dialnet.unirioja.es/descarga/articulo/5916882.pdf

Claes, F. y D eltell, L. (2014). Mus eos s ociales. P erfiles $m$ useísticos en $T$ witter y F acebook 2012-2013. El Profesional de la Información, 23, 594-602. https://doi.org/10.3145/epi.2014.nov.06

Claes, F. y Deltell, L. (2019). Museo social en España: Redes sociales y webs de los museos estatales. El Profesional de la Información, 28, e28 0304. https://doi.org/10.3145/epi.2019.may.04

Cordón-Benito, D. y González-González, D. (2016). Museos y comunicación: los nuevos medios como herramienta de diálogo y sociabilidad de la institución. El uso de Twitter por el Museo del Prado, Museo Thyssen-Bornemisza y Museo Reina Sofía. Fonseca, 12, 149-165. https://10.14201/fjc201612149165

Díaz-Pérez, F., Martínez-Solís, L. y Chaín-Navarro, C. (2015). La gestión de Facebook y Twitter en I os $\mathrm{m}$ useos nav ales y $\mathrm{m}$ arítimos del á mbito hi spanohablante. Erph_Revista electrónica De Patrimonio Histórico, 16, 134-164. https://doi.org/10.30827/erph.v0i16.3527

Eguren-Gutiérrez, L. (1987). Aspecto lúdico del lenguaje. La jitanjáfora, problema lingüístico. Universidad de Valladolid.

Fernández, E . G .; Alarcón, E . V . y Valcarcel, A . S . ( 2020). Tourist f unctionality of t he communication management on Malaga's m useums' s ocial $n$ etworks. [Funcionalidad turística d e la gestión de la c omunicación e $\mathrm{n}$ redes $\mathrm{s}$ ociales $\mathrm{d}$ e $\mathrm{m}$ useos de Málaga] Doxa Comunicación, 30, 309-330. https://doi.org/10.31921/doxacom.n30a16

Fletcher, A. y Le e, M. J. (2012). Current s ocial m edia us es an d e valuations in A merican museums. Museum Management and Curatorship, 27(5), 505-521. https://doi.org/10.1080/09647775.2012.738136

Flores, J . M . (2009). Nuevos m odelos de comunicación, perfiles y tendencias en las redes sociales. Comunicar, 16(33), 73-81. https://doi.org/10.3916/c33-2009-02-007

Fontal, O. (2003). La Educación Patrimonial. Teoría y Práctica en el Aula, el Museo e Internet. Ediciones Trea.

Fontal, O. e Ibáñez-Etxeberria, A. (2017). La investigación en Educación Patrimonial. Evolución y estado actual a través del análisis de indicadores de alto impacto. Revista de educación, 375, 184-214. https://doi.org/10.4438/1988-592X-RE-2016-375-340

Fontal, O y J uanola, R. (2015). La educ ación patrimonial: una d isciplina útil y rentable en el ámbito de la gestión del patrimonio cultural. Cadmo. International Journal of Educational Research, 23(1), 9-25. https://doi.org/10.3280/CAD2015-001002

Gabás, R. (2019). Análisis de Actividad en Redes Sociales. [Trabajo Fin de Grado, Universidad de Zaragoza].

Gabelas. J. A., Marta-Lazo, C. y Aranda, D. (2012). Por qué las TRIC y no las TIC. COMeIN. Revista de los Estudios de Ciencias de la Información y de la Comunicación, 9. ISSN: 1696-3296. https://doi.org/10.7238/c.n9.1221

Gabelas. J. A. y Marta-Lazo, C . (2020). La era TRIC: Factor R-elacional y educomunicación. Ediciones Egregius. 
García-Ceballos, S., Rivero, P., Molina-Puche, S. y Navarro-Neri, I. (2021). Educommunication and A rchaeological $\mathrm{H}$ eritage i $\mathrm{n} I$ taly a nd $\mathrm{S}$ pain: An A nalysis of I nstitutions' Use of Twitter, S ustainability, and C itizen Participation. Sustainability, 13, 1602. https://10.3390/su13041602

Garner, A.; Goldberg, J. y Pou, R. (2016). Collaborative Social Media Campaigns and Special Collections: a c ase s tudy on \#C olorOurCollections, RBM: A Journal of Rare Books, Manuscripts, and Cultural Heritage, 17(2), 100-117. http://dx.doi.org/10.5860/rbm.17.2.9663

Gómez-Vílchez, S . ( 2012). Mus eos es pañoles y r edes s ociales. Telos Cuadernos de Comunicación e Innovación, https://dialnet.unirioja.es/servlet/articulo?codigo=3865845\&orden=335869\&info=link

Gozálvez, V. y C ontreras-Pulido, P. (2014). Empoderar a I a c iudadanía m ediática desde la educomunicación, Comunicar, 42(21), 129-136.

Haller-Baggesen, R. (2014). Augmenting the agora: Media and civic engagement in museums, Mediekultur. Journal of media and communication research, 30(56). 117-131. https://doi.org/10.7146/mediekultur.v30i56.8964

Holdgaard, N. y E kelund-Simonsen, C . (2011). A ttitudes t owards a nd c onceptions of di gital technologies a nd $\mathrm{m}$ edia i $\mathrm{n}$ Danish $\mathrm{m}$ useums. MedieKultur, 50, 100-118. https://doi.org/10.7146/mediekultur.v27i50.3334

Ibáñez-Etxeberria, Á., G ómez, C . J ., F ontal, O . y García-Ceballos, S . ( 2020). Virtual Environments and $\mathrm{A}$ ugmented $\mathrm{R}$ eality Applied to $\mathrm{H}$ eritage $\mathrm{E}$ ducation. An $\mathrm{E}$ valuative Study. Applied Sciences, 10, 2352. https://10.3390/app10072352

Ibáñez-Etxeberria, Á., Vicent, N., Asensio, M. y Cuenca-López, J. M. ( 2014). Lear ning in archaeological sites with mobile devices. Munibe Antropologia-Arkeologia. 65. 313-321. https://10.21630/maa.2014.65.18

ICOM. ( noviembre, 2020) . I nforme: Mus eos, pr ofesionales de los museos y C OVID-19: encuesta d e seguimiento. Disponible online: https://icom.museum/wpcontent/uploads/2020/11/FINAL-ES Follow-up-survey.pdf

Jakobson, R. (1984). Lingüística y poética. En R. Jakobson, Ensayos de lingüística general (pp. 347-395). Ariel.

Kidd, J. (2011). Enacting engagement online: framing social media use for the museum, Information, Technology \&. People, 24(1), 64-77. http://dx.doi.org/10.1108/09593841111109422

Kitungulu, L. (2015). Collaborating to Enliven Heritage Collections. Museum International, 65, 113-122. https://doi.org/10.1111/muse. 12043

Lewis, S., Pea, R., y Rosen, J. (2010). Beyond participation to co-creation of meaning: mobile social $m$ edia i $n$ gen erative I earning c ommunities. Social Science Information, 49(3), 351-369. https://doi.org/10.1177/0539018410370726

Llerena-Iglesias, S. (2016). La comunicación de los museos españoles en Twitter: análisis de la situación y buenas prácticas. [Tesis doctoral, Universidad Carlos III].

Maldonado-Esteras, M.S.( 2015). Educación patrimonial y redes sociales. Análisis y evaluación de acciones en los medios de comunicación social para la definición de una cartografía educativa. [Tesis doctoral, Universidad de Valladolid].

Maldonado-Esteras, M. S. (2017). Educación patrimonial y redes sociales. De la investigación a la acción: El proyecto Educación Patrimonial. Pulso, 40, 97-111. https://revistas.cardenalcisneros.es/index.php/PULSO/article/view/258/211 
Marcelino-Mercedes, G. V . y de la Morena-Taboada, M. (2014). R edes s ociales bas adas en imágenes como her ramienta de comunicación m useística. Mus eos y c entros de ar te Moderno y Contemporáneo de España en Pinterest e Instagram. adComunica. Revista de Estrategias, Tendencias e Innovación en Comunicación, 8, 153 -181. http://dx.doi.org/10.6035/2174-0992.2014.8.9

Marta-Lazo, C. y Gabelas, J. A. (2016). Comunicación digital. Un modelo basado en el Factor $R$-Elacional. Editorial UOC.

Marta-Lazo, C., Marfil-Carmona, R. y Hergueta-Covacho, E. (2016). Aplicación de I as Redes Sociales en el a prendizaje en conectividad: us o del factor relacional e n la dialéctica Twitter, Revista científica electrónica de Educación y Comunicación en la Sociedad del Conocimiento, 16(2). 314-319. https://doi.org/10.30827/eticanet.v16i2.11926

Martín-Cáceres, M. J. y Cuenca-López, J. M. (2015). Educomunicación del patrimonio. Educatio Siglo XXI, 33(1), 33-54. https://10.6018/j/222491

Martínez-Sanz, R . (2012). E strategia c omunicativa digital e n e I m useo. El profesional de la información, 21(4), 391-395. http://dx.doi.org/10.3145/epi.2012.jul.10

Morsy, Z. (Coord.) (1984): La educación en materia de comunicación. UNESCO.

Myna, Z ., Banakh, V., Nahirnyak, A. e I avich, M. (2020). Analysis of the es sence of s ocial networks as a tool for mediatization of the historical and cultural heritage of museums. Paper pr esented at $\mathrm{t}$ he CEUR Workshop Proceedings, 2616, 199-213. http://ceurws.org/Vol-2616/paper17.pdf

Narváez-Montoya, A . ( 2019). Educational c ommunication, e ducommunication, and m edia education: A research and educ ational proposal from a c ulturalist ap proach. Palabra Clave, 22(3), e22311. https://doi.org/10.5294/pacla.2019.22.3.11

Navarro-Neri, I. y Rivero, P . (2019). L os principales museos ar queológicos es pañoles en I as redes s ociales: estudio exploratorio s obre pr ocesos educ omunicativos [ The $\mathrm{m}$ ain Spanish ar chaeological museums i $\mathrm{nt}$ he $\mathrm{s}$ ocial media: ex ploratory $\mathrm{s}$ tudy o $\mathrm{n}$ educommunicative processes]. ENSAYOS. Revista De La Facultad De Educación De Albacete, 34(1), 163-178. https://10.18239/ensayos.v34i1.2043

NEMO. (Mayo 2020) Survey on the impact of the COVID-19 situation on museums in Europe. Final $\mathrm{R}$ eport. $\mathrm{G}$ ermany, $\mathrm{m}$ ay 2 020. disponible online: https://www.nemo.org/fileadmin/Dateien/public/NEMO documents/NEMO COVID19 Report 12.05.20 20.pdf

Pineiro, V., Igartua, J. J. y Rodríguez, I. (2018). Identity-related implications of the dissemination of $c$ ultural $h$ eritage $t$ hrough the I nternet: A $s$ tudy based o $n \mathrm{~F}$ raming Theory. $\begin{array}{llll}\text { Communication } \quad \& \quad \text { Society. } & 31,1 & -21 \text {. }\end{array}$ https://revistas.unav.edu/index.php/communication-andsociety/article/view/35726/30207

Puiggrós-Román E., Tort-Gonzàlez N y F ondevila-Gascón J. F. (2017). Innovación, turismo y TIC: el c aso de I os museos de B arcelona. PASOS: revista de turismo y patrimonio cultural, 15(3), 619-32. http://hdl.handle.net/10230/35932

Rivero, P., Navarro-Neri, I. y Aso, B. (2020). Educommunication Web 2.0 for Heritage: A View From Spanish Museums. En E. J. Delgado-Algarra y J. M. Cuenca-López (Eds.), Handbook of Research on Citizenship and Heritage Education (pp. 449-470). IGI Global. https://doi.org/10.4018/978-1-7998-1978-3.ch021

Rivero, P ., N avarro-Neri, I ., G arcía-Ceballos, S ., y Aso, B . ( 2020). Spanish A rchaeological Museums during C OVID-19 (2020): An E du-Communicative A nalysis of Their Activity on $\mathrm{T}$ witter $\mathrm{t}$ hrough $\mathrm{t}$ he $\mathrm{S}$ ustainable $\mathrm{D}$ evelopment $\mathrm{G}$ oals. Sustainability, 12, 8224 . https://10.3390/su12198224 
Ristol, M. B. (2018). V isibilidad de los museos argentinos en las redes sociales: 2015, en B. Calderón $\mathrm{R}$ oca et al. (Eds.), Nuevas tecnologías e interdisciplinariedad en la comunicación del Patrimonio Cultural (pp. 173-186). Colección A cerVOS. Patrimonio Cultural Iberoamericano.

Russo A., Watkins J. y Groundwater-Smith S. (2009). The impact of social media on informal learning i $\mathrm{nm}$ useums, Educational Media International, 46(2). 153-166 https://doi.org/10.1080/09523980902933532

Samaroudi, M., Rodriguez-Echavarria, K. y Perry L. (2020). Heritage in lockdown: digital provision of memory institutions in the UK and U S of A merica during the C OVID-19 pandemic, Museum Management and Curatorship, 35(4), 337-361, https://doi.org/10.1080/09647775.2020.1810483

Siemens, G. (2005). Connectivism: A learning theory for the digital age. International Journal of Instrunctional Technology and Distance Learning. 1-8. http://www.itdl.org/Journal/Jan 05/article01.htm

Suzić, B., Karlíček, M. y Stříteský, V. (2016), Adoption of s ocial m edia for public relations by museums, Central European Business review 5(2). 5-16. http://dx.doi.org/10.18267/j.cebr.148

Trolle-Gronemann, S ., Kristiansen E. y D rotner K. ( 2015). Mediated c o-construction of museums and audiences on Facebook, Museum Management and Curatorship, 30(3), 174-190. http://dx.doi.org/10.1080/09647775.2015.1042510

UNESCO. (Mayo de 2020). Museums around the world. In the face of Covid-19. France, may 2020. Disponible online: https://unesdoc.unesco.org/ark:/48223/pf0000373530

Villaespesa, E. ( 2018). Evaluación de I a es trategia d igital en I os $m$ useos: métodos y herramientas para web, redes sociales y móviles. Periférica Internacional. Revista para el análisis de la cultural $y$ el territorio. 19,38 -53. https://revistas.uca.es/index.php/periferica/article/view/4902

Viñarás-Abad, M y Caerols-Mateo R. (2016). Redes sociales y patrimonio: cinco museos $\begin{array}{llll}\text { especializados. } & \text { Opción, } & \text { 32(8). } 968 & -988 .\end{array}$ https://www.redalyc.org/articulo.oa?id=31048481055

Zuanni, C. (2017). Italian Museums and Twitter: An analysis of Museum Week. Archeostorie J. Public Archaeology. 1, 119-133. https://archeostoriejpa.eu/papers/2017 4c/

Publicado bajo licencia internacional Creative Commons Attribution-NonCommercial-ShareAlike4.0
(CC-BY-NC-SA 4.0). Se permite copiar, usar, distribuir, transmitir y exhibir públicamente,
siempre que: i) se reconozca la autoría y la fuente original de publicación (revista, editorial y
URL del trabajo); ii) no se utilice con fines comerciales; iii) se mencione la existencia y
especificaciones de esta licencia. 
ANEXOS (tablas 2, 3 y 4).

Tabla 2: aumento de actividad: julio 2020 a mayo 2021

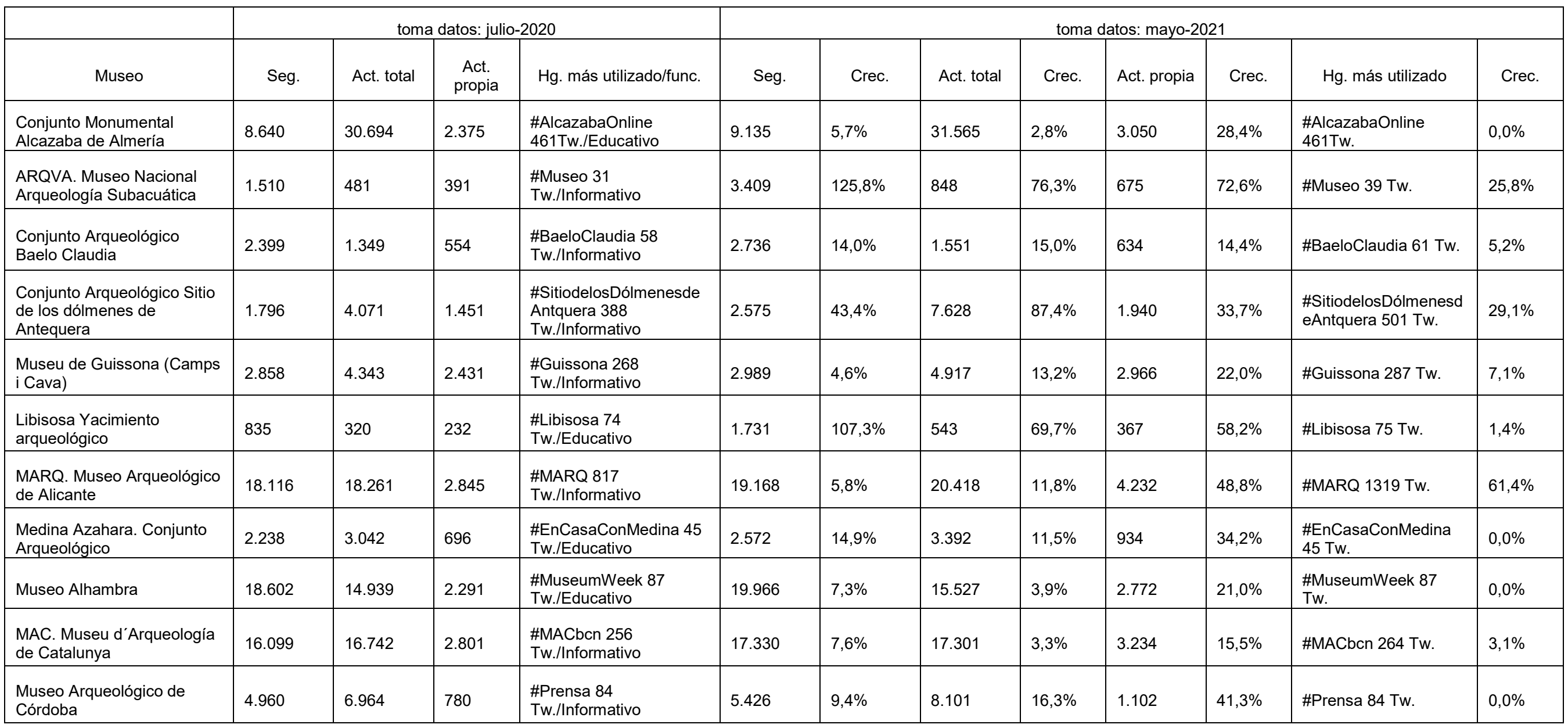




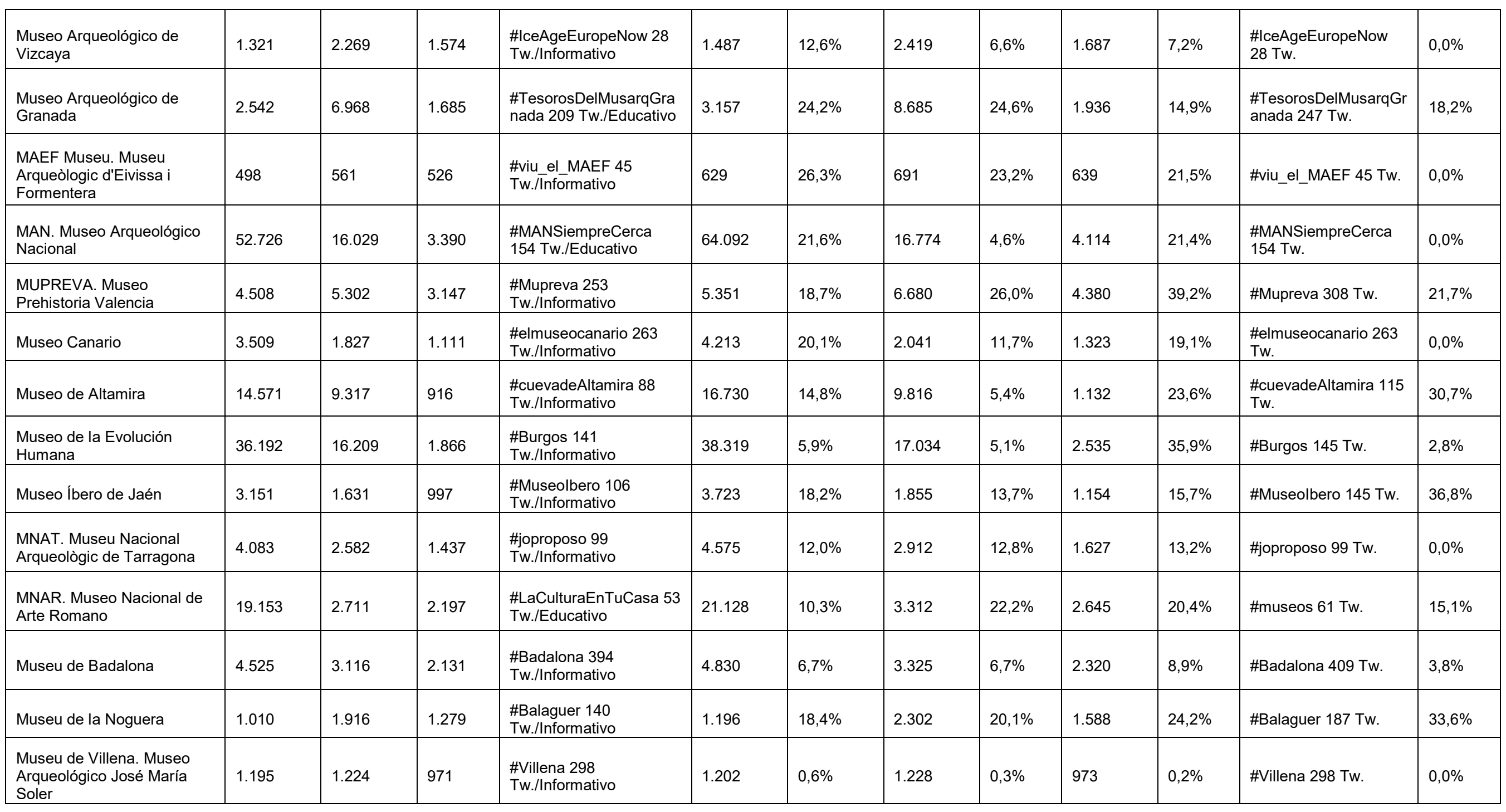




\begin{tabular}{|c|c|c|c|c|c|c|c|c|c|c|c|c|}
\hline $\begin{array}{l}\text { Museu de la història i de la } \\
\text { cultura de Mallorca. } \\
\text { (Pollentia) }\end{array}$ & 5.332 & 4.362 & 2.393 & $\begin{array}{l}\text { \#MuseudeMallorcaDesd } \\
\text { ecasa } 138 \\
\text { Tw./Educativo }\end{array}$ & 5.468 & $2,6 \%$ & 4.514 & $3,5 \%$ & 2.524 & $5,5 \%$ & $\begin{array}{l}\text { \#MuseudeMallorcaDe } \\
\text { sdecasa } 138 \mathrm{Tw} .\end{array}$ & $0,0 \%$ \\
\hline $\begin{array}{l}\text { Museus de les Terres de } \\
\text { l'Ebre i de la Mar de l'Ebre }\end{array}$ & 4.715 & 5.350 & 1.921 & $\begin{array}{l}\text { \#terresdelebre } 173 \\
\text { Tw./Informativo }\end{array}$ & 4.880 & $3,5 \%$ & 5.444 & $1,8 \%$ & 2.124 & $10,6 \%$ & $\begin{array}{l}\text { \#terresdelebre } 173 \\
\text { Tw. }\end{array}$ & $0,0 \%$ \\
\hline $\begin{array}{l}\text { Oiasso. Museo Arqueológico } \\
\text { Irún }\end{array}$ & 2.325 & 4.635 & 1.904 & $\begin{array}{l}\text { \#Oiasso } 238 \\
\text { Tw./Informativo }\end{array}$ & 2.443 & $5,1 \%$ & 4.897 & $5,7 \%$ & 2.138 & $12,3 \%$ & \#Oiasso 266 Tw. & $11,8 \%$ \\
\hline $\begin{array}{l}\text { Vilamuseu. Red de } \\
\text { Monumentos y Museos de } \\
\text { Villajoyosa }\end{array}$ & 1.904 & 2.767 & 2.112 & $\begin{array}{l}\text { \#Villajoyosa } 540 \\
\text { Tw./Informativo }\end{array}$ & 2.032 & $6,7 \%$ & 2.891 & $4,5 \%$ & 2.199 & $4,1 \%$ & \#Villajoyosa 545 Tw. & $0,9 \%$ \\
\hline Villa Romana La Olmeda & 1.315 & 1.787 & 1.728 & $\begin{array}{l}\text { \#LaOImeda } 786 \\
\text { Tw./Informativo }\end{array}$ & 1.577 & $19,9 \%$ & 1.979 & $10,7 \%$ & 1.917 & $10,9 \%$ & \#LaOlmeda 836 Tw. & $6,4 \%$ \\
\hline
\end{tabular}

*Seg: Seguidores; Act. Tot.: Actividad total (tweets, retweets, contenido compartido); Act. Or.: tweets originales; Hg. más utilizado/func.: hashtag más utilizado, tweets totales y función predominante; Crec.: crecimiento porcentual. 
Tabla 3: Museos “arqueológicos” y “de sitio”, multimedialidad y funciones del lenguaje predominante.

*Nota: 1.1: Solo texto; 1.2: Texto y URL del museo o externa; 1.3: Solo imagen; 1.4: Texto e imagen; 1.5: Texto, imagen y URL del museo o externa; 1.6: Vídeo integrado en Twitter

\begin{tabular}{|c|c|c|c|c|c|c|c|c|c|c|c|c|c|c|c|c|}
\hline \multirow{2}{*}{ Museo } & \multirow{2}{*}{ Hashtags COVID 19} & \multirow{2}{*}{ Tweets } & \multicolumn{9}{|c|}{ V.1 Multimedialidad: tipos de códigos y combinaciones } & \multicolumn{5}{|c|}{ V.2 Funciones del lenguaje } \\
\hline & & & 1.1 & 1.2 & 1.3 & 1.4 & 1.5 & 1.6 & 1.7 & 1.8 & 1.9 & 2.1 & 2.2 & 2.3 & 2.4 & 2.5 \\
\hline $\begin{array}{l}\text { Conjunto Monumental } \\
\text { Alcazaba de Almería }\end{array}$ & $\begin{array}{l}\text { \#TuAlcazabaOnLine } \\
\text { \#AlcazabaOnline }\end{array}$ & 461 & 0 & 20 & 1 & 156 & 172 & 0 & 21 & 0 & 91 & 148 & 76 & 212 & 19 & 6 \\
\hline $\begin{array}{l}\text { MARQ. Museo Arqueológico } \\
\text { de Alicante }\end{array}$ & \#quedateencasaconeIMARQ & 181 & 6 & 8 & 0 & 69 & 13 & 0 & 85 & 0 & 0 & 77 & 1 & 102 & 1 & 0 \\
\hline $\begin{array}{l}\text { Medina Azahara. Conjunto } \\
\text { Arqueológico }\end{array}$ & \#EnCasaConMedina & 45 & 4 & 9 & 0 & 23 & 9 & 0 & 0 & 0 & 0 & 0 & 0 & 45 & 0 & 0 \\
\hline Museo Alhambra & \#TuMuseoOnLine & 36 & 0 & 2 & 0 & 30 & 4 & 0 & 0 & 0 & 0 & 1 & 1 & 34 & 0 & 0 \\
\hline Museo Arqueológico Córdoba & \#QuedateEnCasa & 60 & 0 & 3 & 0 & 55 & 1 & 0 & 1 & 0 & 0 & 1 & 0 & 57 & 0 & 2 \\
\hline Museo de Altamira & \#AltamiraDesdeCasa & 30 & 1 & 7 & 0 & 17 & 5 & 0 & 0 & 0 & 0 & 6 & 9 & 13 & 1 & 1 \\
\hline $\begin{array}{l}\text { MAN. Museo Arqueológico } \\
\text { Nacional }\end{array}$ & \#MANSiempreCerca & 154 & 13 & 7 & 0 & 61 & 50 & 0 & 16 & 1 & 6 & 15 & 18 & 121 & 0 & 0 \\
\hline $\begin{array}{l}\text { MNAR. Museo Nacional de } \\
\text { Arte Romano }\end{array}$ & $\begin{array}{l}\text { \#EnCasaconelMNAR } \\
\text { \#LaCulturaEnTuCasa } \\
\end{array}$ & 53 & 0 & 3 & 33 & 0 & 13 & 0 & 3 & 1 & 0 & 11 & 0 & 42 & 0 & 0 \\
\hline $\begin{array}{l}\text { MNAT. Museu Nacional } \\
\text { Arqueològic de Tarragona }\end{array}$ & \#elMNATaCasa & 19 & 4 & 2 & 0 & 4 & 9 & 0 & 0 & 0 & 0 & 4 & 12 & 3 & 0 & 0 \\
\hline $\begin{array}{l}\text { Museu de la història i de la } \\
\text { cultura de Mallorca. } \\
\text { (Pollentia) }\end{array}$ & \#MuseudeMallorcaDesdecasa & 138 & 30 & 3 & 0 & 96 & 8 & 0 & 1 & 0 & 0 & 2 & 0 & 136 & 0 & 0 \\
\hline & TOTAL & 1177 & 58 & 64 & 34 & 511 & 284 & 0 & 127 & 2 & 97 & 265 & 117 & 765 & 21 & 9 \\
\hline & TOTAL & $\%$ & 4,9 & 5,4 & 2,9 & 43,4 & 24,1 & 0 & 10,8 & 0,2 & 8,2 & 22,5 & 9,9 & 65 & 1,8 & 0,8 \\
\hline
\end{tabular}

sin texto; 1.7: Texto y vídeo integrados en Twitter; 1.8: Texto y vídeo integrados en Twitter y URL del museo o externa; 1.9: Encuesta (pregunta y se puede seleccionar una o varias opciones); 2.1: Expresiva/emotiva; 2.2: Apelativa/conativa; 2.3: Referencial/representativa; 2.4: Poética; 2.5: Lúdica. 
Tabla 4: Museos "arqueológicos" y "de sitio", hashtag más utilizado y análisis educomunicativo

\begin{tabular}{|c|c|c|c|c|c|c|c|c|c|c|c|c|c|c|c|c|}
\hline \multirow{2}{*}{ Museo } & \multirow{2}{*}{ Hashtags COVID 19} & \multirow[t]{2}{*}{ Tweets } & \multicolumn{5}{|c|}{ V.3 Objetivo predominante } & \multicolumn{4}{|c|}{ V.4 Factor R-elacional } & \multicolumn{5}{|c|}{ V.5 Aprendizaje sugerido } \\
\hline & & & 3.1 & 3.2 & 3.3 & 3.4 & 3.5 & 4.1 & 4.2 & 4.3 & 4.4 & 5.1 & 5.2 & 5.3 & 5.4 & 5.5 \\
\hline $\begin{array}{l}\text { Conjunto Monumental Alcazaba } \\
\text { de Almería }\end{array}$ & \#TuAlcazabaOnLine\#AlcazabaOnline & 461 & 191 & 153 & 2 & 72 & 43 & 109 & 22 & 18 & 312 & 104 & 157 & 48 & 4 & 148 \\
\hline $\begin{array}{l}\text { MARQ. Museo Arqueológico de } \\
\text { Alicante }\end{array}$ & \#quedateencasaconelMARQ & 181 & 105 & 2 & 0 & 1 & 73 & 0 & 0 & 0 & 181 & 0 & 94 & 2 & 1 & 84 \\
\hline $\begin{array}{l}\text { Medina Azahara. Conjunto } \\
\text { Arqueológico }\end{array}$ & \#EnCasaConMedina & 45 & 32 & 0 & 13 & 0 & 0 & 0 & 0 & 0 & 45 & 0 & 45 & 0 & 0 & 0 \\
\hline Museo Alhambra & \#TuMuseoOnLine & 36 & 16 & 0 & 19 & 0 & 1 & 0 & 0 & 0 & 36 & 1 & 33 & 0 & 0 & 2 \\
\hline Museo Arqueológico Córdoba & \#QuedateEnCasa & 60 & 53 & 0 & 6 & 0 & 1 & 0 & 0 & 0 & 60 & 0 & 58 & 0 & 0 & 2 \\
\hline Museo de Altamira & \#AltamiraDesdeCasa & 30 & 12 & 12 & 3 & 2 & 1 & 6 & 0 & 6 & 18 & 7 & 12 & 4 & 0 & 7 \\
\hline $\begin{array}{l}\text { MAN. Museo Arqueológico } \\
\text { Nacional }\end{array}$ & \#MANSiempreCerca & 154 & 116 & 19 & 10 & 2 & 7 & 17 & 1 & 1 & 135 & 15 & 91 & 2 & 21 & 25 \\
\hline $\begin{array}{l}\text { MNAR. Museo Nacional de Arte } \\
\text { Romano }\end{array}$ & \#EnCasaconelMNAR/\#LaCulturaEnTuCasa & 53 & 33 & 12 & 2 & 1 & 5 & 0 & 0 & 14 & 39 & 0 & 37 & 4 & 3 & 9 \\
\hline $\begin{array}{l}\text { MNAT. Museu Nacional } \\
\text { Arqueològic de Tarragona }\end{array}$ & \#eIMNATaCasa & 19 & 3 & 12 & 0 & 1 & 3 & 1 & 0 & 11 & 7 & 4 & 4 & 4 & 1 & 6 \\
\hline \multirow[t]{3}{*}{$\begin{array}{l}\text { Museu de la història i de la } \\
\text { cultura de Mallorca. (Pollentia) }\end{array}$} & \#MuseudeMallorcaDesdecasa & 138 & 110 & 0 & 23 & 1 & 4 & 0 & 0 & 0 & 138 & 0 & 98 & 0 & 37 & 3 \\
\hline & TOTAL & 1177 & 671 & 210 & 78 & 80 & 138 & 133 & 23 & 50 & 971 & 131 & 629 & 64 & 67 & 286 \\
\hline & TOTAL & $\%$ & 57 & 18 & 7 & 6,8 & 12 & 11,3 & 1,9 & 4,2 & 82,5 & 11 & 53 & 5,4 & 6 & 24 \\
\hline
\end{tabular}

*Nota: 3.1: Transmisivo; 3.2: Participativo; 3.3: Da claves para comprender; 3.4: Fomenta valores de apropiación y respeto; 3.5: Disfrute y transferencia; 3.6: No hay (información); 4.1: I nteracción ( demostrativa); 4.2: R eflexión (interpretativa); 4. 3: ( Co)creación ( constructiva); 4. 4: N o hay ; 5. 1: C onductismo; 5 .2: C ognitivismo; 5. 3: C onstructivismo; 5. 4: Conectivismo; 5.5: No hay. 